\title{
Zur Frage über den Anteil der Leber am Kreatininstoffwechsel. Von
}

E. S. London und N. Boljarski.

(Der Redaktion zugegangen am 20. August 1909.)

Dank der Vervollkommnung und Vereinfachung der quantitativen Bestimmungsmethode des Kreatins und Kreatinins durch Folin sind in der letzten Zeit sehr viel Arbeiten erschienen, die dazu dienen sollen, die Rolle dieser Substanzen im allgemeinen Stoffwechsel aufzuklären (c. J. C. van Hoogenhuyze und Verploegh, Ostertag und Wolff, Cathcart, Benedict, Underhill und Kleiner, Gottlieb u. a.). Die Resultate dieser Untersuchungen führen uns unter anderem $\mathrm{zu}$ der Annahme, daß das Kreatin sich als Stoffwechselprodukt in verschiedenen Organen bildet, unter denen die Leber eine wichtige Stelle einnimmt, und daß das in den Organen stetig gebildete Kreatin teils oxydiert wird, teils aber in Kreatinin umgewandelt wird, bei welchem Prozesse wiederum die Leber eine wichtige Rolle spielt.

Diese Ansichten brachten uns auf den Gedanken, festzustellen, wie sich die Ausscheidung des Kreatins und Kreatinins im Harn bei solchen Hunden verhält, bei denen die Leberfunktion infolge chirurgischer Eingriffe und vor allem unter Ableitung des Pfortaderbluts in die v. cava (Ecksche Hunde) verändert ist. Äußere Umstände hinderten uns, diese Frage systematisch und allseitig $\mathrm{zu}$ studieren, was wir allerdings in der nächsten Zeit auszuführen beabsichtigen. Vorläufig begnügen wir uns, die Resultate anzugeben, welche wir an zwei Eckschen Hunden, die für andere Zwecke dienten, erhalten haben.

Die gewonnenen Zahlen, die in der vorliegenden Tabelle zusammengestellt sind, zeigen folgendes: 
E. S. London und N. Boljarski,

\begin{tabular}{|c|c|c|c|c|}
\hline Datum & Fütterungsart & $\begin{array}{l}\text { Harn-N } \\
\text { in } \mathrm{g}\end{array}$ & $\begin{array}{c}\text { Kreatinin } \\
\text { in } \mathrm{g}\end{array}$ & $\begin{array}{c}\text { Kreatin } \\
\text { in } \mathrm{g}\end{array}$ \\
\hline & \multicolumn{4}{|c|}{ Eckscher Hund Nr. 1} \\
\hline 11. IV. 09 & Hunger & 6,400 & 0,278 & 0,143 \\
\hline 12. & Milch & 8,040 & 0,303 & 0,076 \\
\hline 13. & Mich und Brot & 4,000 & 0,197 & 0,048 \\
\hline 14. , & Milch & 5,676 & 0,212 & 0,023 \\
\hline 15. & Milch $+4 \mathrm{~g}$ nucleinsaures $\mathrm{Na}$ & 8,030 & 0,247 & 0,024 \\
\hline 16. & » & 8,010 & 0,392 & 0,049 \\
\hline 17. & D & 9,352 & 0,507 & 0,091 \\
\hline 18. & Milch und Brot & 5,017 & 0,235 & 0,038 \\
\hline 19. & $\triangleright$ & 5,500 & 0,344 & 0,028 \\
\hline 20. & $\triangleright$ & 6,020 & 0,331 & 0,024 \\
\hline 25. VI. 09 & Hunger & 5,305 & 0,270 & 0,291 \\
\hline 26. 》 & Milch & 6,010 & 0,287 & 0,017 \\
\hline 27. » & Milch $+1 \mathrm{~g}$ Kreatinin & 5,831 & 0,363 & 0,212 \\
\hline 28. \$ & $» \quad+1$ g Kreatin & 5,756 & 0,567 & 0,070 \\
\hline 29., & > & 6,129 & 0,571 & 0,060 \\
\hline 30. & $\triangleright$ & 5,930 & 0,270 & 0,026 \\
\hline \multirow[t]{2}{*}{31.} & , & 6,329 & 0,229 & 0,022 \\
\hline & \multicolumn{4}{|c|}{ Eckscher Hund Nr. 2} \\
\hline 14. 》 & Milch und Brot & 5,928 & 0,201 & 0,015 \\
\hline 15. & , & 5,672 & 0,361 & 0,058 \\
\hline 16. $\gg$ & Milch und Brot $+1 \mathrm{~g}$ Tryptophan & 4,480 & 0,432 & 0,056 \\
\hline 17. & +2 & 5,481 & 0,324 & 0,016 \\
\hline 18. > & Milch und Brot & 5,115 & 0,239 & 0,097 \\
\hline 19. & , & 3,537 & 0,306 & 0,022 \\
\hline 20. & Hunger & 5,575 & 0,083 & 0,144 \\
\hline 21. & Milch und Brot & 4,781 & 0,079 & 0,042 \\
\hline 22. » & Milch und Brot $+0,75 \mathrm{~g}$ Kreatinin & 5,795 & 0,183 & 0,072 \\
\hline 23. & Milch und Brot & 6,104 & 0,234 & 0,044 \\
\hline 6. VII. 09 & Milch (Appetitlosigkeit) & 4,385 & 0,781 & 0,396 \\
\hline 7. $>$ & Milch und Brot (Appetitlosigkeit) & 6,780 & 0,322 & 0,618 \\
\hline 8. $>$ & Dasselbe & 6,345 & 0,290 & 0,725 \\
\hline $9 . \gg$ & Fleisch & 4,380 & 0,334 & 0,242 \\
\hline 10. & Hunger $\int$ (Iypiscner Anall) & 3,451 & 0,261 & 0,258 \\
\hline 11. -14 . & Milch und Brot & 5,831 & 1,620 & 0,066 \\
\hline
\end{tabular}


1. An den Hungertagen wies das Kreatin bedeutend höhere Zahlen auf, als in den Fütterungstagen.

2. Die Darreichung des Kreatinins mit dem Futter hatte keine Vermehrung desselben im Harn zur Folge; die Zuführung des Kreatins mit dem Futter gab keine Vergrößerung der Kreatinmenge im Harn, wohl aber des Kreatinins (am Versuchstage und am folgenden).

3. Nucleinsaures Natrium wirkte nicht in irgend merklicher Weise auf die Ausscheidung von Kreatin oder Kreatinin ein.

4. Am größten waren die Schwankungen der Ausscheidung zuerst des Kreatinins und dann des Kreatins einige Tage vor dem Anfall und am Tage des Anfalls, jedoch wurden hinterher prompt die früheren Verhältnisse wiederhergestellt.

Die Bestimmungen führten wir mit dem Kolorimeter Dubosq-Péllin aus, welches außerordentlich genaue Messungen gestattet. 